\title{
Usher syndrome
}

INSERM

\section{Source}

INSERM. (1999). Orphanet: an online rare disease and orphan drug data base. Usher syndrome. ORPHA:886

Usher syndrome (US) is characterized by the association of sensorineural deafness (usually congenital) with retinitis pigmentosa and progressive vision loss. 